\title{
Incidence of Inflammatory Bowel Disease in Gampaha district: details of the Sri Lankan component of the Asia-Pacific Crohn's and Colitis Epidemiology Study*
}

\begin{abstract}
A Kasturiratne ${ }^{1}$, M N F Mufeena ${ }^{1}, K_{\text {K C D Mettananda }}{ }^{1}$, N Fernandopulle ${ }^{2}$, S Rajindrajith ${ }^{1}$, P R Waraketiya ${ }^{1}$, S K Weerasinghe ${ }^{1}$, A Ranaweera ${ }^{1}$, S J de S Hewavisenthi ${ }^{1}$, A P de Silva ${ }^{1}$, H J de Silva $^{1}$
\end{abstract}

(Index words: IBD, ulcerative colitis, Crohn's disease, epidemiology, Asia)

\section{Summary}

The aim of this report is to provide details of the methodology and results of the Sri Lankan component of the Asia-Pacific Crohn's and Colitis Epidemiology Study. Fourteen state and private hospitals with specialist services in the Gampaha and Colombo districts were kept under surveillance over a 12 month period to recruit patients with newly diagnosed Inflammatory Bowel Disease (IBD) who were permanent residents of the Gampaha district. Thirty five cases (ulcerative colitis-21, Crohn's disease-13, IBD-undetermined-1) were detected, giving a crude annual IBD incidence of 1.59 per 100,000 population.

Ceylon Medical Journal 2014; 59: 16-18

\section{Introduction}

A number of recent reports from the Asia-Pacific region indicate an increase in the incidence and prevalence of Inflammatory Bowel Disease (IBD) [1-3]. However, robust epidemiological studies from the region are few, and most data are derived from hospital databases or hospital-based cross-sectional studies [3]. The recent AsiaPacific Crohn's and Colitis Epidemiology Study (ACCESS) determined the incidence and phenotype of IBD in 8 countries across Asia, which included Sri Lanka, and in Australia [4]. This large scale population based study (involving a population of more than 30 million) reported a crude annual overall incidence of 1.37 per 100,000 population in Asia, and 23.67 per 100,000 in Australia. The incidence of IBD varied throughout Asia, but was still much lower than in Western populations (including
Australia) [1].

The aim of this report is to provide more details of the methodology employed and the results obtained in the Sri Lankan component of the study.

\section{Methods}

The Sri Lankan component of ACCESS was carried out in the Gampaha district. This district, which encompasses an area of $1341 \mathrm{~km}^{2}$ has a population of 2,200,000 and a fairly well defined catchment area for its hospitals. As one of the most developed and populous in Sri Lanka, the population of the district is likely to be stable. There is a reasonable urban-rural mix and high literacy rates (>95\%). The ethnic mix is $91 \%$ Sinhalese, 3.6\% Tamil, 3.8\% Muslim and 1.7\% others [Department of Census and Statistics of Sri Lanka].

The district is served by 10 state sector hospitals (that offer free health care); four offering specialist services (Colombo North Teaching Hospital, and Base Hospitals Negombo, Gampaha and Wathupitiwela) and six that do not. It also has two private hospitals which have facilities for both endoscopy and histology. A proportion of patients from the Gampaha district are also likely to seek treatment in nearby hospitals in the adjoining Colombo district. A survey among Medical Officers-in-Charge confirmed that state sector hospitals without specialist services in both Gampaha and Colombo districts neither treated nor followed-up IBD patients; suspected cases were referred for specialist care. This was also the case during a previous prevalence study of IBD in the two districts conducted in 2007-2008 [5]. Therefore, the four

${ }^{1}$ Faculty of Medicine, University of Kelaniya, Ragama and ${ }^{2}$ National Hospital of Sri Lanka, Colombo, Sri Lanka.

Correspondence: HJdeS, e-mail: <hjdes@sltnet.lk>. Received 21 August 2013 and revised version accepted 21 October 2013. Competing interests: none declared.

\footnotetext{
*This paper provides details of the methodology and results of the Sri Lankan component of the Asia-Pacific Crohn's and Colitis Epidemiology Study [Reference 4].
} 
specialist hospitals and two private hospitals in the Gampaha district, and the National Hospital of Sri Lanka, Colombo, Sri Jayawardenapura General Hospital, Base Hospital Avissawella, and five major private hospitals in the Colombo district were kept under surveillance for one year from April 2011. Selected specialist and other doctors in these 14 hospitals were contacted by telephone and/or visited every two to four weeks. In addition, patient registers, and endoscopy and histology records in all 14 hospitals under surveillance were examined during the study period in order to detect any cases that may have been "missed".

Incident IBD cases diagnosed between April 2011 and March 2012 who were permanent residents of the Gampaha district were enrolled. Patient identities were cross-checked to avoid duplication. Clinical information was obtained by both review of case records and patient interviews after written informed consent. The diagnosis of IBD had to satisfy accepted clinical, endoscopic and radiological criteria with histological confirmation [6]. Other diagnoses, including infections, intestinal tuberculosis, amoebiasis, and non-steroidal anti-inflammatory drug induced ulceration, were rigorously excluded. Patient details were entered onto a web-based database. Cases were only included in the final analysis if the diagnosis remained certain at six month follow-up.

Crude incidence rates were calculated based on the number of patients diagnosed compared with the total population at risk. Projected population data by age and sex were obtained from the Department of Census and Statistics. Incidence rates were reported with 95\% confidence intervals (CI), assuming a Poisson distribution. Incidence rates were age standardized using the World Health Organization's Standard Population [7].

Ethical approval for the study was obtained from the Ethical Review Committee of the Faculty of Medicine, University of Kelaniya, Sri Lanka.

\section{Results}

Over the one year period 35 new IBD cases were identified; 6 (17.1\%) had been "missed” initially, and were detected from endoscopy and histology records. There were 21 (60\%) with ulcerative colitis (UC), 13 (37.2\%) with Crohn's disease (CD), and 1 (2.8\%) with IBD-undetermined (IBD-U). The crude annual incidence of IBD was 1.59 per 100,000 population (95\% CI, 1.11-2.21) [UC 0.95 (0.59-1.46), CD 0.59 (0.32-1.01), IBD-U 0.05 (0.01-0.19)] (Table). The male:female ratios were, overall IBD - 16:19, UC - 8:13, CD 7:6. The median age at diagnosis was 34 years (range 4 to 66 ) for all IBD patients. A family history of IBD was reported by 2/35 (5.7\%) of patients.
Table. Incidence of IBD in the Gampaha District (per 100,000 persons) [4]

\begin{tabular}{lcccr}
\hline & IBD & UC & CD & IBD- $U$ \\
\hline Crude annual incidence & 1.59 & 0.95 & 0.59 & 0.05 \\
Age adjusted incidence* & 1.55 & 0.94 & 0.56 & 0.04 \\
Incidence assuming: & & & & \\
20\% cases missed & 1.93 & & & \\
30\% cases missed & 2.21 & & & \\
\hline
\end{tabular}

IBD - Inflammatory bowel diseases; UC - ulcerative colitis; CD - Crohn's disease; IBD-U - Inflammatory bowel disease undetermined

* Age-specific incidence rates were standardized to the World Health Organization's Standard Population Distribution [7].

\section{Discussion}

Some developed countries have systems that allow for registration and retrieval of disease specific health information, for example, regarding cancer, IBD etc. Except for Japan, which has a national IBD registry, no such system exists in Asia. In such situations epidemiological studies on diseases such as IBD, where the diagnosis is based on histology, are necessarily based on case detection when patients seek health care. A good epidemiological study for IBD should have a well-defined catchment area and up-to-date population data, good diagnostic facilities, uniform criteria of case definition, a common protocol and an established referral system (8). Our study satisfied several of these criteria. The Gampaha district is one of the most urbanised and developed districts and staffing and diagnostic facilities in hospitals are among the best in the country making significant migration to other parts of the country for employment or health care unlikely. Demographic data are up-to-date and a high literacy rate is likely to positively impact on health seeking behaviour. There is, howerer, no formal referral system.

It is possible that patients with mild disease in the community, who either did not seek or were not referred for care, would have been missed, although most people with a chronic disease such as IBD are likely to seek medical care at some point in their illness. This may have led to an underestimation of the true incidence of IBD in Gampaha district although we used a fairly comprehensive approach to detect new cases. However, the need to select only hospitals staffed by specialists for surveillance made case detection easier and would have improved the accuracy and uniformity of the diagnosis of IBD.

The prevalence of IBD (6.5 per 100,000) in a Sri Lankan population has been previously reported from the results of a cross sectional hospital based study in the Gampaha and Colombo districts conducted in 2007-2008 (5). 
However, there have been no reports on its incidence. The incidence of IBD in this population (1.59 per 100,000) is low compared to Western populations but similar to some in Asia [4]. The female preponderance for UC, the low incidence in children and less familial clustering are notable differences from Western population studies [1]. The latter two findings are to be expected in situations where IBD is still emerging. Longitudinal studies from the West during the past 50 years have shown an increasing incidence of UC first, followed by a rise in the incidence of CD [9]. Consistent with studies from other developing countries [10], UC is still the predominant disease in our population. In Asian countries that have become westernized, the ratio of UC to CD appears to be narrowing [4], and as CD was very rarely diagnosed in the past, a similar trend may be occurring in Sri Lanka.

\section{Acknowledgements}

We are grateful to the specialists in the hospitals where the study was conducted for their support and granting access to their patients.

\section{References}

1. Loftus EV. Clinical epidemiology of inflammatory bowel disease. Gastroenterology 2004; 126: 1504-17.

2. Ouyang Q, Tandon R, Goh KL, et al. The emergence of inflammatory bowel disease in the Asian Pacific region. Current Opinion in Gastroenterology 2005; 21: 408-13.

3. de Silva HJ, de Silva NR, de Silva AP, Jewell DP. Emergence of inflammatory bowel disease 'beyond the West': do prosperity and improved hygiene have a role? Transactions of the Royal Society of Tropical Medicine and Hygiene 2008; 102: 857-60.

4. Ng SC, Tang W, Ching J, et al. On behalf of the Asia-Pacific Crohn's and Colitis Epidemiologic Study (ACCESS) study group. Incidence and Phenotype of Inflammatory Bowel Disease, Based on Results from the Asia-Pacific Crohn's and Colitis Epidemiologic Study. Gastroenterology 2013; 145: 158-65.

5. Niriella MA, De Silva AP, Dayaratne HGAK, et al. Prevalence of inflammatory bowel disease in two districts of Sri Lanka: a hospital based survey. BMC Gastroenterology 2010; 10: 32.

6. Lennard-Jones JE. Classification of inflammatory bowel disease. Scandinavian Journal of Gastroenterology 1989; 24: 2-6.

7. Ahmad OB, Boschi-Pinto C, Lopez AD. Age standardization of rates: a new WHO standard. Global Programme on Evidence for Health Policy Discussion Paper Series: No. 31. Geneva: World Health Organization; 2001.

8. Shivananda S, Lennard Jones J, Logan R, et al. Incidence of inflammatory bowel disease across Europe: is there a difference between north and south? Result of the European Collaborative Study on Inflammatory Bowel Disease (EC-IBD). Gut 1996; 39: 690-7.

9. Ekbom A, Helmick C, Zack M, et al. The epidemiology of inflammatory bowel disease: a large, population-based study in Sweden. Gastroenterology 1991; 100: 350-8.

10. Thia KT, Loftus EV Jr, Sandborn WJ, et al. An update on the epidemiology of inflammatory bowel disease in Asia. American Journal of Gastroenterology 2008; 103: 3167-82. 